\title{
Darf ich nebenbei selbstständig arbeiten?
}

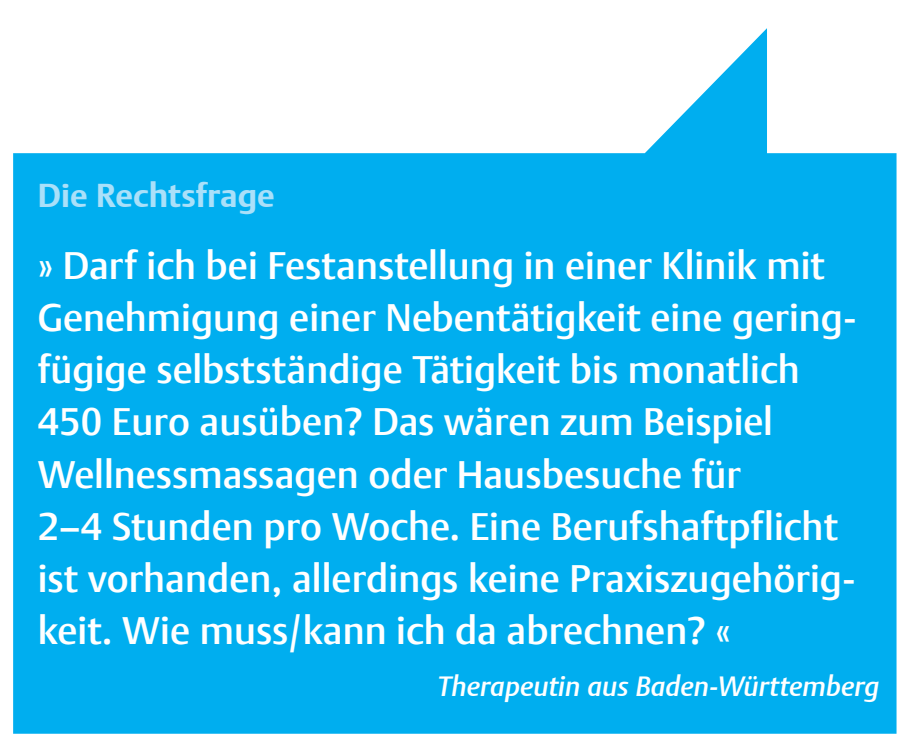

Die Antwort unseres Experten

Zunächst ist es ohne Weiteres möglich, eine selbstständige Nebentätigkeit mit einem Monatsumsatz von bis zu 450 Euro aufzunehmen, wenn der Arbeitgeber zustimmt. Bis zu dem genannten Verdienst dürfte zudem eine Versicherungsfreiheit bei der Rentenversicherung für die selbstständige Tätigkeit bestehen.

Problematischer ist allerdings die Frage des Tätigkeitsspektrums. Denn die Abrechnung gegenüber der gesetzlichen Krankenversicherung ohne Praxiszulassung scheidet aus. Eine Abrechnung über die Praxis eines Dritten als freier Mitarbeiter ist im Hinblick auf die Sozialversicherungsbeiträge mit einem hohen Risiko behaftet. Eine ausführliche Darstellung dieses Problems finden Sie im Artikel „Wie sicher ist freie Mitarbeit?" in physiopraxis 6/14, S. 59.

Die zu erbringenden Leistungen dürfen zudem keine Heilbehandlungen sein, da sonst ein Verstoß gegen das Heilpraktiker- gesetz vorläge. Heilbehandlungen sind Ärzten und Heilpraktikern vorbehalten. Mit einer (sektoralen) Heilpraktikererlaubnis dürften Sie jedoch auch Heilbehandlungen gegenüber Privatzahlern erbringen.

Bei einem Umsatz von bis zu 450 Euro pro Monat können Sie für Ihre Leistungen umsatzsteuerfreie Rechnungen ausstellen. Das gilt auch für umsatzsteuerpflichtige Leistungen wie Yoga, Pilates, Nordic Walking oder Wellnessmassagen (außer bei Heilbehandlungen ist das immer der Fall). Denn mit einem Umsatz bis 450 Euro pro Monat gilt die Kleinunternehmerregelung im Sinne des Umsatzsteuergesetzes. Mit einem entsprechenden Vermerk auf den Rechnungen ist eine Steuerfreiheit gegeben.

Das heißt: Jeder Therapeut, der nebenberuflich Leistungen anbieten will, ist in erster Linie auf Privatzahlerangebote beschränkt. Sollten Sie also keine Heilpraktikererlaubnis haben, dürften Sie neben- beruflich keine Heilbehandlungen durchführen - allenfalls Wellnessmassagen oder Präventionsangebote. Philipp Groteloh

\section{$\Rightarrow$ Wirft auch Ihr Berufsalltag rechtliche Fragen auf? Dann schreiben Sie an Simone.Gritsch@thieme.de.}

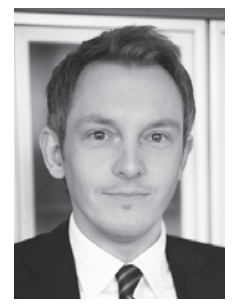

Dr. Philipp Groteloh ist seit 2007 Rechtsanwalt und seit 2012 Fachanwalt für Verwaltungsrecht. 